\title{
СОВЕРШЕНСТВОВАНИЕ ЦИФРОВОЙ ЭКОНОМИКИ В ИННОВАЦИОННОЙ ПОЛИТИКЕ РОССИЙСКИХ КОМПАНИЙ.
}

\section{IMPROVING THE DIGITAL ECONOMY IN THE INNOVATION POLICY OF RUSSIAN COMPANIES}

\section{S. Doguchaeva}

Summary. Today, a dynamic ecosystem based on an IT technology environment and intuitive devices provides a global platform on which leading companies can create new customer service capabilities based on Big Data. Digitalization of the economy contributes to the growing need for highly qualified specialists who are able to work with modern technologies.

Machine learning and Artificial Intelligence is a tool that can fundamentally change the methods for evaluating a number of economic processes. New approaches and Big Data analysis help companies make real-time decisions. The high speed of decision-making and the exclusion of the human factor make it possible to speak of the superiority of this technology over man. Today, artificial intelligence has a wide potential for application in business.

Keywords: digitalization of the economy, information technology, economic potential, the Internet of things, data analysis, artificial intelligence, machine learning, big data.

\author{
Догучаева Светлана Магомедовна \\ К.ф.-м.н., доцент, Финансовый университет при \\ Правительстве Российской Федерации, г. Москва \\ sv-doguchaeva@yandex.ru
}

Аннотация. Сегодня динамичная экосистема, основанная на технологической ИТ- среде, интуитивных устройствах, обеспечивает глобальную платформу, на которой ведущие компании позволяют создавать на основе Больших данных, новые возможности по работе с клиентами. Цифровизация экономики способствует росту потребности в высококвалифицированных специалистах, способных работать с современными технологиями.

Машинное обучение и Искусственный интеллект - инструмент, который может кардинально изменить методы оценки ряда экономических процессов. Новые подходы и анализ Больших данных помогают компаниям принимать решения в режиме реального времени. Высокая скорость принятия решений и исключение человеческого фактора позволяют говорить и превосходстве данной технологии над человеком. На сегодняшний день у искусственного интеллекта есть широкий потенциал применения в бизнесе.

Ключевые слова: цифровизация экономики, информационные технологии, экономический потенциал, интернет вещей, анализ данных, искусственный интеллект, машинное обучение, большие данные.
$\mathbf{T}$ ехнологии искусственного интеллекта постепенно выходят на плато продуктивности, интерес у пользователей вызывают технологии автоматизированного машинного обучения и бизнес-приложения со встроенными механизмами. Растет спрос на платформы искусственного интеллекта, предоставляемые в виде услуги, и соответствующие облачные сервисы. Они оказывают огромное влияние на цифровую экономику в целом, способствуя повышению продуктивности в компаниях и, как следствие, дают толчок для конкуренции и роста индивидуальных предприятий. Анализ больших объемов данных и искусственного интеллекта стали фундаментом новой волны роста производительности труда.

На сегодняшний день имеет большое значение формирование и развитие понимания особенностей и возможностей современных и перспективных информационно-коммуникационных технологий, составляющих основу цифровой экономики. Анализируя работы [2,5], следует понимать, что проникновение цифровых тех- нологий в экономику будет иметь свои последствия, как положительные, так и отрицательные, внедрение современных технологий способствует появление новых источников дохода, что скажется на экономическом росте компаний. Внедрение инноваций не простой пусть, где специалисты, обладающие навыками внедрения новых методов, способны объединить их компетенции с бизнес-лидерами, способными произвести необходимые организационные изменения. Успешное внедрение машинного обучения требует целостной стратегии, которая позволит вовлечь в этот процесс все бизнес-функции на всех уровнях экономического управления компаний. [4] Примерами использования являются системы распознавания лиц, разработанные для прогнозирования поведения клиентов, виртуальные помощники (чат-боты), а также системы на основе машинного обучения, управляющие динамическим ценообразованием.

Искусственный интеллект (AI) и облачные составляющие - это инновационные технологии, так как главное преимущество использования облачной модели потре- 
бления продуктов искусственного интеллекта для компаний в том, что «Облако» делает Al доступным, снижает порог входа для клиентов, которые готовы использовать искусственный интеллект в своих продуктах и услугах. Использование искусственного интеллекта, машинного обучения и глубокого обучения требует значительных вычислительных мощностей. По исследованию ведущих специалистов в области ИТ-инноваций, далеко не каждая компания, организация могут приобрести столь дорогое оборудование и имеют соответствующих специалистов в области искусственного интеллекта для повышения эффективности и результативности экономики. [1]

Структура качества больших данных неизбежно ориентирована на оперативные аспекты усилий компании по обеспечению качества данных, что не мало важно в экономике. Чтобы поднять качество экономических данных на новый уровень, компании могут использовать интеллектуальный подход к качеству этих данных, который дает возможность достичь гораздо более широкого уровня понимания, анализа, отчетности. Это, в свою очередь, позволит компаниям собирать и хранить историческую информацию о качестве данных, включая частоту изменения элемента и частоту ошибочной пометки данных - хорошие показатели уровня ошибок, а также качества правил проверки. В более широком смысле это даст возможность критического анализа любых возникающих проблем с данными и эффективности ключевых элементов управления данными в современном анализе цифровой экономики.

Сегодня автоматизация производства привела к фундаментальному прогрессу в промышленности, и, как следствие, в экономике и других сферах жизни, пришло время роботизации интеллектуального труда. Искусственный интеллект способен освободить человека не только от тяжелого труда и рутинных обязанностей, но и помочь ему в творческой деятельности. Согласно недавнему исследованию признанного лидера в области аналитики PWC, искусственный интеллект (Al) и интернет вещей (ІоT) могут внести до \$15,7 трлн. в мировую экономику в 2030 году, что больше, чем текущий объем производства Китая и Индии. [3] Этот вклад был рассчитан на основе повышения производительности труда и усовершенствования продуктов, которые будут стимулировать потребительский спрос. Единственным крупным недостатком является то, что они требуют подключения к сети интернет и, соответственно, могут подвергаться хакерским атакам, что не совсем приятно, а иногда и опасно для частных потребителей, а применение их в промышленности может быть чревато техногенными катастрофами.

Вопрос о том, в какой степени и кем должны быть проверены алгоритмы искусственного интеллекта, до сих пор остается предметом дискуссий. По мнению ведущих экономистов, для повышения экономической эффективности, ИТ-аналитики стремятся обеспечить некоторую уверенность в том, что алгоритмы искусственного интеллекта грамотно разработаны. Данные технологии работают так, как ожидали аналитики отрасли, они достаточно прозрачны для пользователей, и они не подвергают компанию риску из-за непреднамеренных результатов.

Современный уровень развития информационных технологий позволяет создавать системы (платформы), в которых «зашиты» все существенные условия отношений между субъектами и которые при реализации определенного алгоритма создают новую запись, которая порождает новые права и обязанности субъектов этих отношений, а часто и третьих лиц. В результате образуется новый актив или происходит переход прав на существующий. Именно по такой модели работают алгоритмы, которые сейчас называют «смарт-контрактами», и идет рост потока конкурентоспособных инноваций

В аналитической компании IDC полагают, что успех в экономике ждет компании, которые в своей кадровой политике будут опираться на такие три элемента как культура, пространство и ресурсы. Речь идет о корпоративной культуре, отвечающей всем новым реалиям, гибком совмещении виртуального и физического рабочего места и, конечно, о людях.

Рекомендации IDC, касающиеся рабочего пространства, следующие:

- расширение возможности сотрудников с помощью технологий, которые способствуют инновациям;

- улучшение взаимодействия и обеспечение безопасной работы из любой точки мира. Согласно прогнозам компании, уже к 2021 году 65\% компаний перейдут к модели будущего рабочего пространства - гибкой, интеллектуальной, совмещающей виртуальную и физическую рабочую среду, что положительно повлияет на будущее развитие цифровой экономики во всем мире. По мнению ведущих специалистов в цифровой экономике, компаниям следует иметь в виду, что их «сотрудниками» могут стать не только живые люди, но и цифровые, работа будущего будет выполняться как человеком, так и машинами, а это значит, что придется решать вопросы, связанные в том числе и с их взаимодействием.

По прогнозам аналитиков [8], к 2024 году 50\% структурированных повторяющихся задач будут автоматизированы, а 20\% работников, занятых в наукоемких задачах, будут иметь программное обеспечение с использова- 
нием искусственного интеллекта или другие цифровые технологии в качестве «коллеги». По мнению вице-президентов ведущих российских компаний, сегодня главная проблема заключается в подготовке «креативных людей», специалистов, которые не просто обладают знаниями, а быть максимально готовыми к обучению и самообучению, то есть по их мнению, именно такие люди нужны для цифровой экономики.

Цифровизация финансовых услуг в России переходит на следующую ступень своего развития. По данным исследования KPMG «Цифровые технологии в российских банках», опросившего в текущем году 100 крупных российских компаний, в том числе топ-20 банков, 86\% руководителей банков заявили о наличии программ цифровой трансформации. Этот показатель выше рынка, где около 64\% компаний заняты цифровизацией. По данным KPMG, банкиры рассчитывают, что цифровизация повысит операционную эффективность и сократит издержки, среди проблем они отмечают нехватку компетентных кадров и незрелость текущих процессов.[6]

Применение машинного обучения можно во многих отраслях, и практически везде оно позволяет существенно улучшить процессы. Некоторые из них уже разработали специальные средства, ежедневно тестируя влияние различных аспектов, такие как изменения цен, дизайн упаковки или веб-страниц, привлекая реальных клиентов. [10] Многие ведущие корпорации не случайно позиционируют себя как двигатель когнитивного бизнеса во всем мире. Когнитивный бизнес осуществляется посредством использования более продвинутых инструментов для работы с динамическими данными, что помогает доминировать на рынке.

Сегодня в сфере творческой деятельности человек по-прежнему имеет преимущество перед машиной: сложные коммуникации, экспертное мышление, гибкость, креативность. Машина пока не умеет слушать, выстраивать беседу и договариваться с источниками. Тем не менее искусственный интеллект может помочь чело- веку оптимизировать его труд, может помочь сделать контент более персонализированным и адресным.

Привлечение юридических компаний, имеющих опыт работы в законах о больших данных, может помочь провести оценку пробелов в соответствии с правовыми требованиями. Эти оценки принимают форму опроса и оценивают технические средства контроля конфиденциальности в соответствии с требованиями законодательства в процессе развития цифровой экономики. Сегодня анализируя работы [9,11], эксперты отрасли экономики готовы работать с ведущими ИТ-директорами для обеспечения всеобъемлющей стратегии управления данными.

Использование современных технологий управления данными обеспечивает технические и технологические возможности для решения проблем по соответствию требованиям. Решение заключается в правильном балансе выбора и наличии правильной инфраструктуры, которые касаются не только экономики. Все это способствует стимулированию модернизации отраслей экономики за счет передачи инновационных знаний и технологий в рамках единого информационно-технологического пространства.

В заключении, следует отметить, что меняющийся правовой ИТ-ландшафт, сложность и различия в правилах конфиденциальности с большими данными, искусственного интеллекта, касающиеся экономики в целом, представляют собой некоторые проблемы. Требования ИТ-безопасности и конфиденциальности совпадают во многих ИТ-областях, общие правила защиты данных, изменения, вызванные защитой конфиденциальности - это небольшая часть из множества изменений, связанных с конфиденциальностью, которые имеют побочные эффекты не только в экономике. По мнению ведущих аналитиков [7], чтобы ориентироваться и решать проблемы в меняющейся правовой ИТ-среде, компании должны тесно сотрудничать с ведущими специалистами по вопросам конфиденциальности.

\section{ЛИТЕРАТУРА}

1. Разработки Искусственного интеллекта// (Электронный ресурс). Режим доступа: https://tlg.fyi/s/bolshiedannye/209// свободный (дата обращения 26.03.2020).

2. Искусственный интеллект изменят бизнес в ближайшем будущем // (Электронный ресурс). Режим доступа: https://lookatnews.info/post/ / свободный (дата обращения 06.04.2020).

3. Машинное обучение сегодня// (Электронный ресурс). Режим доступа: https://cnews.ru/articles/2019-11-12// свободный (дата обращения 17.03.2020).

4. Система управления Искусственным интеллектом // (Электронный ресурс). Режим доступа: https://ria.ru/20191107/1560642841.html// свободный (дата обращения 23.03.2020).

5. Технологии Искусственного интеллекта https://cnews.ru/articles/2019-1 ogij // свободный (дата обращения 20.04.2020).

6. Технологии, вышедшие на плато продуктивности // (Электронный ресурс). Режим доступа: https://compress.ru/article.aspx?id=21903\#01// свободный (дата обращения 03.04.2020). 
7. Цифровая экономика Российской федерации// (Электронный ресурс). Режим доступа: https://www.gks.ru/anketa1-4// свободный (дата обращения 21.04.2020).

8. Экономика управления большими данными // (Электронный ресурс). Режим доступа: https://oecd-russia.org/analytics/ekonomika // свободный (дата обращения 11.03.2020).

9. Влияние Больших данных на экономику// (Электронный ресурс). Режим доступа: https://itcrumbs.ru/texnologii-big-dat // свободный (дата обращения 15.04.2020)

10. Машинное обучение в экономике // (Электронный ресурс). Режим доступа: https://itcrumbs.ru/texnologii-big-dat// свободный (дата обращения 19.04.2020).

11. Искусственный Интеллект// (Электронный ресурс). Режим доступа: http://www.techportal.ru/glossary/artificial_intelligence.html// свободный (дата 0бращения 10.04.2020).

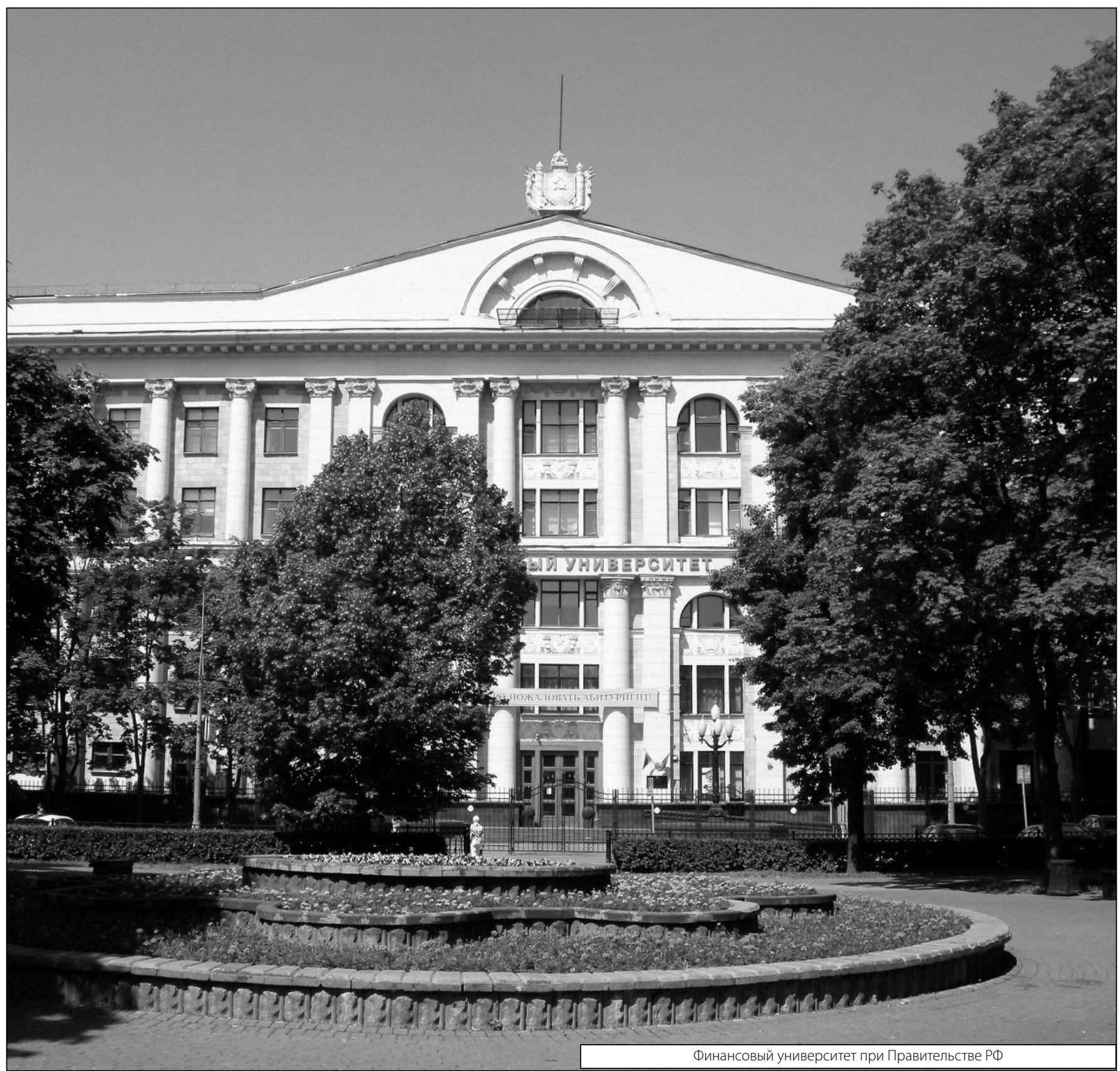

